\title{
MASTER
}

C00-1105-111

\section{THERMOLUMINESCENCE OF LiF:Mg AS A FUNCTION OF $R$}

\author{
by \\ D. W. Pearson and J.R. Cameron \\ Department of Physics \\ University of Wisconsin \\ Madison, Wisconsin
}

A sample of LiF:Mg (66ppm Mg by spectrographic analysis)* was ground and seived to obtain a powder between 70 and 180 mesh Tyler. The powder was annealed for one hour at $400^{\circ} \mathrm{C}$ and quenched rapidly in air to $15^{\circ} \mathrm{C}$ by pouring onto a large aluminum block. To facilitate handling, small gelatin capsules were filled with enough powder to obtain four measu'rements per capsule. Each capsule was irradiated to a known dose with a ${ }^{137} \mathrm{Cs}$ source, using $5 \mathrm{~mm}$ of lucite to insure uniform electron buildup. The TL was measured within ten minutes after irradiation. Four glow curves were recorded at each irradiation level using an EMI 6256 photomultiplier, a Keithley 610A electrometer, and a Moseley $\mathrm{X}-\mathrm{Y}$ recorder. Fig. 1 shows a typical glow curve. The $210^{\circ} \mathrm{C}$ peak occurs at approximately the same temperature as the principal dosimetry peak TLD-100 LiF*. These curves were integralied with a planimeter and averaged to obtann TL as a function of $R$. The data, normalized to unity at 100R, are shown in Fig. 2. This material is about a factor of thirty less sensitive to radiation than the standard dosimeter materia 1 TLD-100.LiF. In addition it would not be as satisfactory for dosimeter purposes as its main glow peak occurs at a low temperature and is less stable. Fig. 3 shows the $T L / R$ 


\section{DISCLAIMER}

This report was prepared as an account of work sponsored by an agency of the United States Government. Neither the United States Government nor any agency Thereof, nor any of their employees, makes any warranty, express or implied, or assumes any legal liability or responsibility for the accuracy, completeness, or usefulness of any information, apparatus, product, or process disclosed, or represents that its use would not infringe privately owned rights. Reference herein to any specific commercial product, process, or service by trade name, trademark, manufacturer, or otherwise does not necessarily constitute or imply its endorsement, recommendation, or favoring by the United States Government or any agency thereof. The views and opinions of authors expressed herein do not necessarily state or reflect those of the United States Government or any agency thereof. 


\section{DISCLAIMER}

Portions of this document may be illegible in electronic image products. Images are produced from the best available original document. 
as a function of $R$. Errors are estimated to be less than

5\%. Additional work to fit these data with the mathematical mode $1^{(1)}$ is in progress.

* Purchased from Harshaw Chemical Co., Cleveland, Ohio.

(1) Cameron, J.R., and Zimmerman, D.W. - T.L vs R in LiF: A Proposed Mathematical Mode1 - AEC Report C00-1105102 (1965). 


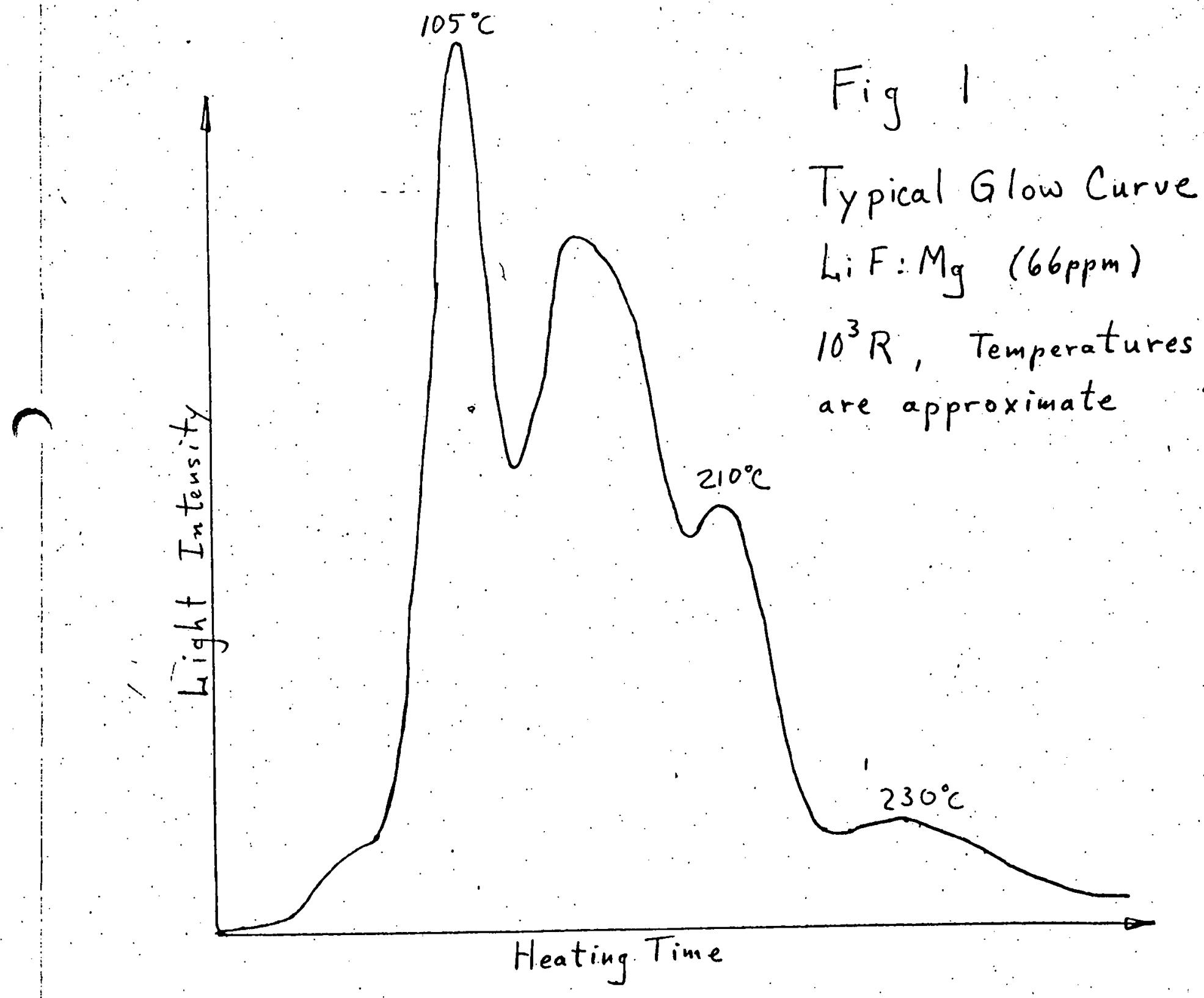


Luminescence in Arbitrary Units

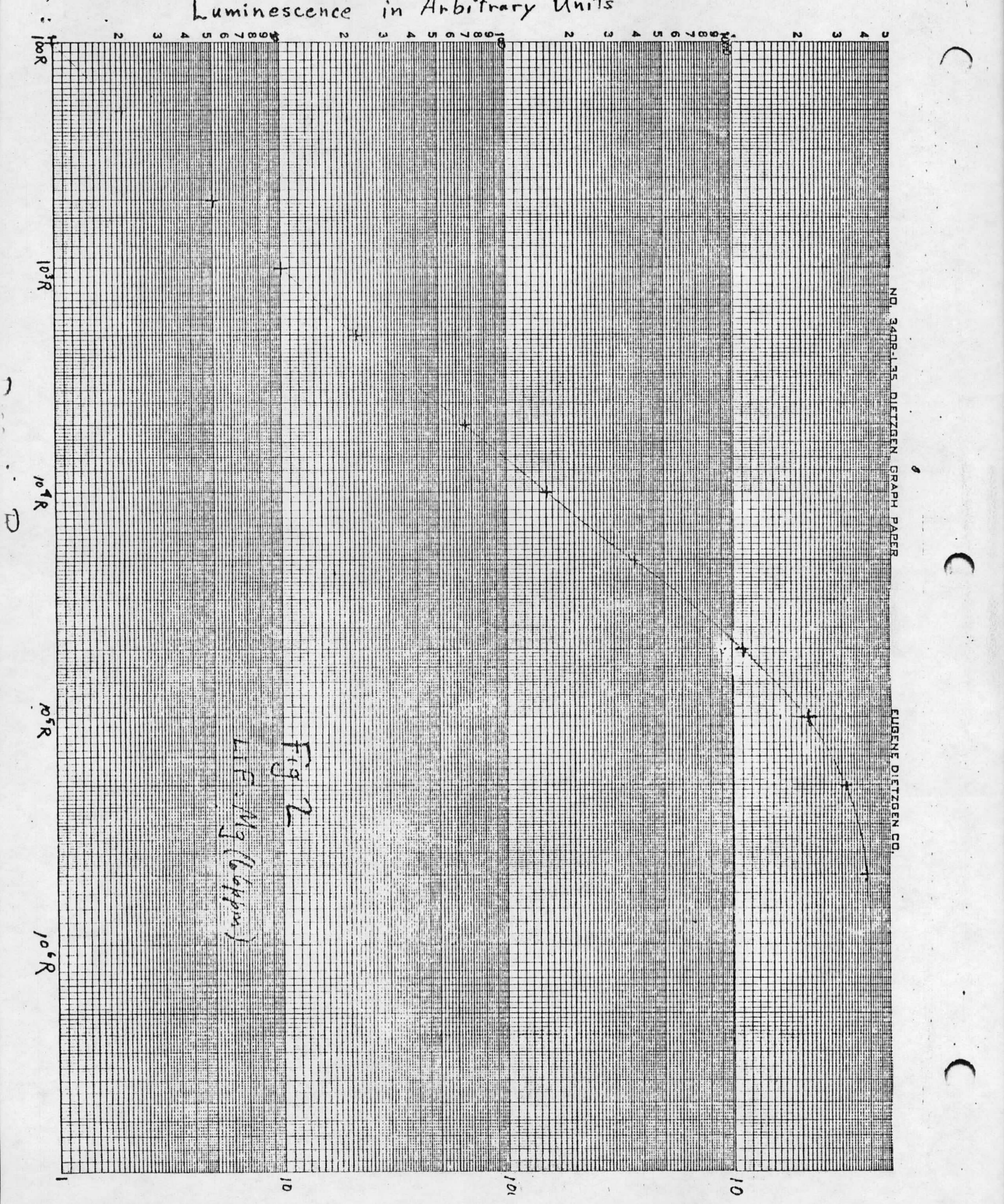




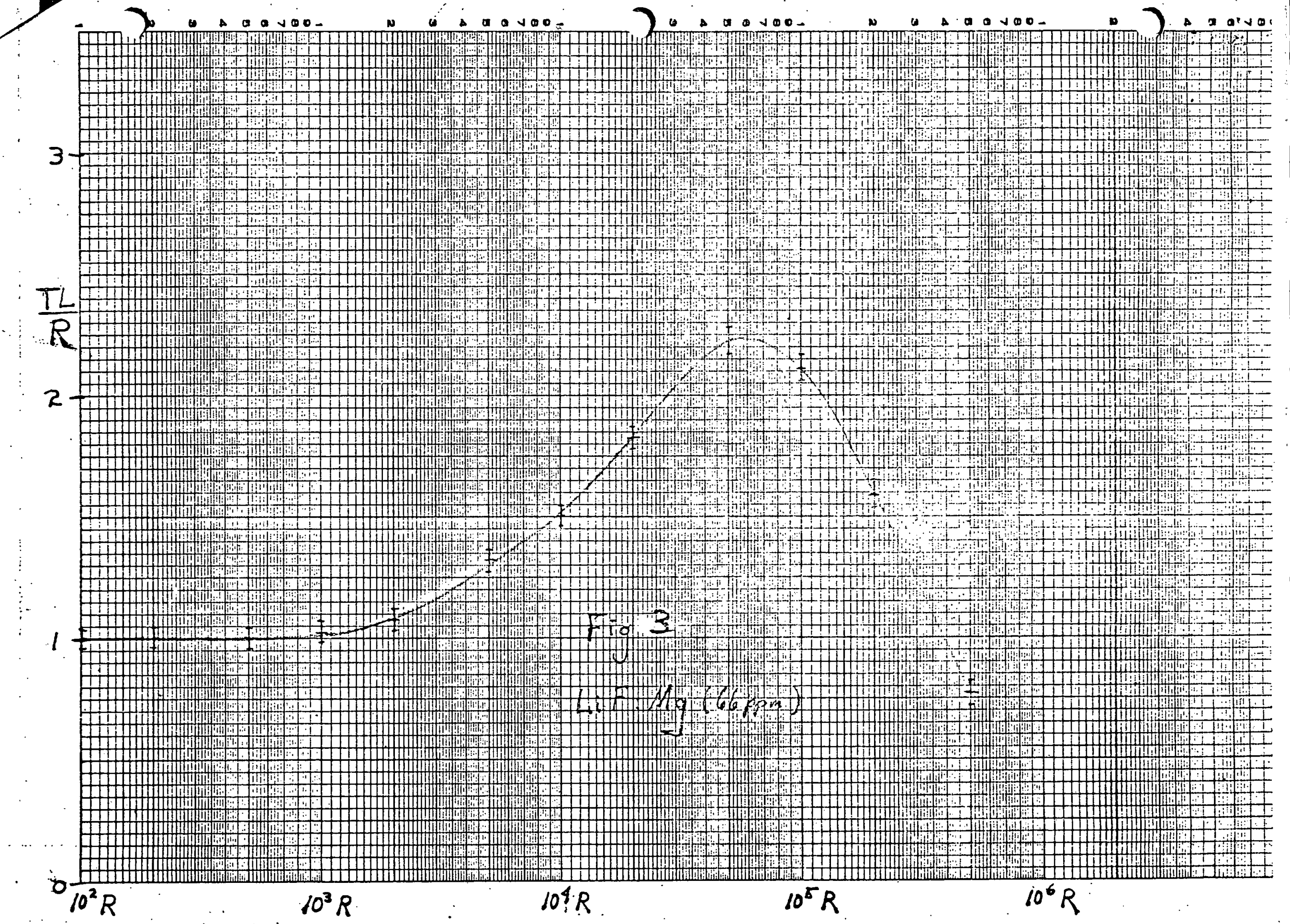

